\title{
ESTUDO DO COMPORTAMENTO DE ÓLEO DE SOJA E DE ARROZ REUTILIZADOS EM FRITURAS SUCESSIVAS DE BATATA
}

\author{
PAULA VERGARA* \\ ANA PAULA WALLY** \\ VANESSA RIBEIRO PESTANA** \\ CAROLINE BASTOS** \\ RUI CARLOS ZAMBIAZI ${ }^{\star \star *}$
}

\begin{abstract}
Este trabalho teve como objetivo avaliar parâmetros de qualidade para os óleos de arroz e soja após sucessivas frituras. Doze lotes de $200 \mathrm{~g}$ de batata cortada tipo palito foram levadas à fritura em dois diferentes tipos de óleo (arroz e soja). Os métodos analíticos aplicados para avaliação da alteração nos óleos incluíram a determinação de ácidos graxos livres, índice de peróxido, antes e após a fritura. Efetuou-se a avaliação sensorial das amostras de óleo quanto aos atributos cor e odor após períodos pré-determinados de fritura, e avaliação sensorial das batatas quanto aos atributos cor, odor e sabor. O óleo de arroz apresentou maior estabilidade e menor interferência nas características das batatas durante os sucessivos processos de fritura. O óleo de soja evidenciou alterações sensoriais significativas na cor e odor a partir do quarto período de fritura e o óleo de arroz a partir do oitavo período. As alterações sensoriais de cor, odor e sabor das batatas ocorreram no oitavo período de uso do óleo de soja e acima da décima segunda vez de uso do óleo de arroz.
\end{abstract}

PALAVRAS-CHAVE: ÓLEOS VEGETAIS - DEGRADAÇÃO; ÓLEOS VEGETAIS ESTABILIDADE; ANÁLISE SENSORIAL.

* Discente do Curso de Química de Alimentos, Universidade Federal de Pelotas (UFPel), Pelotas/RS

** Mestrandas do Programa de Pós-Graduação em Ciência e Tecnologia Agroindustrial, UFPel, Pelotas/RS.

*** Professor titular do Departamento de Ciência dos Alimentos e do Programa de Pós-Graduação em Ciência e Tecnologia Agroindustrial, UFPel, Pelotas/RS (e-mail: zambiazi@ufpel.tche.br).

B.CEPPA, Curitiba, v. 24, n. 1, p. 207-220, jan./jun. 2006 


\section{INTRODUÇÃO}

O consumo de alimentos fritos e pré-fritos congelados, como batata e empanados, induz maior ingestão de óleos e gorduras através dos processos de fritura (DOBARGANES e PÉREZ-CAMINO, 1991). Parte do óleo utilizado como meio de transferência de calor é absorvida pelo alimento, que pode variar de 5 a $40 \%$, tornando-se um ingrediente do produto. Tal fato evidencia a necessidade de se utilizar meio de fritura de alta qualidade, a qual deve ser mantida por períodos prolongados (CELLA, REGITANO-D'ARCE e SPOTO, 2002).

Durante o processo de fritura, o alimento entra em contato com óleo em temperaturas entre $180-190^{\circ} \mathrm{C}$ que provocam uma série complexa de reações e a produção de numerosos compostos de degradação. Tais reações alteram a qualidade funcional, sensorial e nutricional dos alimentos, podendo atingir níveis em que não se consegue mais manter sua qualidade (ANS, MATTOS E JORGE, 1999; ARAUJO, 1999).

As principais formas de deterioração lipídica durante o processo de fritura incluem hidrólise, oxidação e polimerização. A hidrólise envolve inicialmente a quebra de ligações do éster no glicerídio com formação de ácidos graxos livres, monoglicerídios, diglicerídios e glicerol. Essa reação é favorecida com a presença de água em altas temperaturas, podendo resultar em produtos com alta volatilidade e alta reatividade química (ROJO e PERKINS, 1987; MORETTO e FETT, 1999; ZAMBIAZI, 2005).

A oxidação consiste no processo degradativo que ocorre quando o oxigênio atmosférico ou dissolvido no óleo reage com ácidos graxos insaturados. As reações químicas envolvidas no processo de oxidação de óleos são extremamente complexas e geram em seus estádios intermediários produtos sensorialmente inaceitáveis, com odores e sabores desagradáveis para o consumo humano. O processo pode ser catalisado por resíduos de metais ou alta temperatura (ARAUJO, 1999; ZAMBIAZI, 1999).

A polimerização ocorre quando duas ou mais moléculas de ácidos graxos combinam-se como consequência das alterações do processo de oxidação e altas temperaturas, principalmente em operações de 
frituras. Os polímeros resultantes promovem aumento na viscosidade do óleo, que favorece maior encharcamento na superfície da massa de certos alimentos, causando impressão visual e alteração sensorial bastante desagradáveis (CHRISTOPOULOU e PERKINS, 1989; MORETTO e FETT, 1998) .

Alimentos submetidos à fritura em óleos reutilizados e mantidos sob aquecimento constante podem proporcionar a formação de produtos inaceitáveis pelo sabor residual de ranço, sensação excessivamente gordurosa ao paladar e alteração da textura (COSTANETO, FREITAS e WASZCZYNSKYJ, 1995; PINTO, 2003).

A intensidade com que as reações degradativas ocorrem durante o processo de fritura depende de fatores como temperatura e tempo de fritura, relação superfície/volume do óleo, tipo de óleo empregado, tipo de aquecimento, adição de óleo não utilizado sobre o óleo de fritura e natureza do alimento submetido à fritura (LIMA e GONÇALVES, 1994; LOLOS, OREOPOULOU e TZIA, 1999).

O tipo de óleo representa o componente mais crítico no sistema de fritura. Sua degradação depende da proporção de ácidos graxos saturados/insaturados e em menor grau da presença de componentes naturais como tocoferóis, clorofilas e esteróis. Óleos vegetais que apresentam grandes proporções de ácidos graxos poliinsaturados favorecem processos oxidativos com maior intensidade (LOLOS, OREOPOULOU e TZIA, 1999; ZAMBIAZI e ZAMBIAZI, 2000).

No Brasil, é comum o emprego de óleo de soja (em termos nacionais) e óleo de arroz (principalmente no sul do país) para processos de frituras de alimentos em estabelecimentos comerciais. O óleo de soja contém cerca de $15 \%$ de ácidos graxos saturados, $22 \%$ de ácido oléico, $54 \%$ de ácido linoléico e $7,5 \%$ de ácido linolênico. O óleo de arroz contém cerca de $19 \%$ de ácidos graxos saturados, $42 \%$ de ácido oléico, $36 \%$ de ácido linolêico e $1,8 \%$ de ácido linolênico (ZAMBIAZI, 1997).

O objetivo deste estudo foi verificar a estabilidade dos óleos de soja e de arroz, com diferentes composições em ácidos graxos, utilizados em sucessivas frituras descontínuas de batata. 


\section{MATERIAL E MÉTODOS}

\subsection{MATERIAL}

Foram utilizadas batatas oriundas do mercado local de Pelotas (RS) e óleos de arroz e de soja de marcas comerciais.

\subsection{PROCESSO DE FRITURA}

As batatas foram descascadas, manualmente, cortadas em tiras (forma de "palito") com diâmetro médio de 0,8 x 0,8 cm e comprimento em torno de 5,2 cm, lavadas em água corrente e secas em papel toalha.

As batatas cortadas foram separadas em 24 porções de $200 \mathrm{~g}$, sendo 12 porções de $200 \mathrm{~g}$ para serem submetidas à fritura em óleo de soja e outras 12 para fritura em óleo de arroz.

Colocaram-se as batatas nos óleos aquecidos em frigideira esmaltada a $180^{\circ} \mathrm{C}$ durante 5 minutos, tempo suficiente para adquirir aspecto visual característico de batata frita. Finalizada a fritura, as batatas foram escorridas por 3 minutos em cesto de aço inoxidável e secas em papel toalha absorvente durante 2 minutos.

Deixou-se o óleo utilizado resfriar para temperatura de $40^{\circ} \mathrm{C}$ (ao término da fritura), repetindo-se o processo de fritura nos dois tipos de óleos para as outras 11 porções de batata. Desta forma, simulou-se o processo de fritura descontínua usado em restaurantes, lanchonetes e domesticamente.

\subsection{ANÁLISES}

Amostras de cada tipo de óleo foram coletadas anteriormente à fritura e após a $1^{\mathrm{a}}, 4^{\mathrm{a}}, 8^{\mathrm{a}}$ e $12^{\mathrm{a}}$ frituras para serem analisadas quanto ao conteúdo em ácidos graxos livres e índice de peróxido (AOCS, 1992). Além da análise físico-química efetuou-se teste sensorial para avaliar os atributos de cor e odor dos óleos. Antes das análises, as amostras foram filtradas para remover resíduos de batatas presentes no meio.

Amostras de batata frita foram coletadas após frituras nos dois óleos utilizados pela $1^{\mathrm{a}}, 4^{\mathrm{a}}, 8^{\mathrm{a}}$ e $12^{\mathrm{a}}$ vez para serem avaliadas sensorialmente 
quanto aos atributos de cor, odor e sabor.

Equipe treinada de oito julgadores analisaram as amostras pelo teste de avaliação de atributos. Utilizou-se escala não-estruturada de 9 centímetros, segundo as normas da ABNT (1998), em que o julgador assinala na escala o ponto que melhor descreve a intensidade percebida para cada atributo. Para a avaliação dos óleos, a identificação do atributo cor ocorreu por comparação com padrão do óleo comestível respectivo. Para o atributo cor, o extremo inferior da escala correspondeu ao termo "idêntico ao padrão" e o extremo superior a "mais escuro que o padrão". Para o atributo odor, o extremo inferior correspondeu a "odor característico" e o extremo superior a "odor a ranço". Na avaliação sensorial das batatas fritas foram utilizados os extremos inferior "dourado claro" e superior "dourado escuro" (cor), inferior "odor característico" e superior "odor a ranço" (odor) e inferior "sabor característico" e superior "sabor estranho" (sabor).

A análise foi realizada com iluminação branca (luz fluorescente), sendo as amostras servidas em recipientes de porcelana. $\mathrm{Na}$ avaliação das amostras dos óleos foram utilizados $20 \mathrm{~mL}$ e das batatas fritas 4 pedaços (tiras) para cada julgador.

\section{RESULTADOS E DISCUSSÃO}

\subsection{ANÁLISES FÍSICO-QUÍMICAS}

A acidez pode revelar parcialmente o estado de conservação dos óleos e gorduras. Conforme se aumenta o número de frituras pode ocorrer maior hidrólise do óleo devido a alta temperatura e troca de umidade do alimento para o meio de fritura, com conseqüente aumento no conteúdo de ácidos graxos livres (MASSON, 1997).

A Figura 1 apresenta o comportamento da acidez dos óleos de arroz e soja durante o processo de fritura.

O conteúdo da acidez inicial do óleo de soja $(0,15 \mathrm{~g}$ de ácido oléico $/ 100 \mathrm{~g})$ mostrou-se praticamente igual à do óleo de arroz $(0,13 \mathrm{~g}$ de ácido oléico/100 g). O teor de acidez do óleo de soja não apresentou diferença significativa até o $4^{\circ}$ período de fritura $(0,16 \mathrm{~g}$ de ácido 
oléico/100 g) e o óleo de arroz até o 8ํㅜ período $(0,14 \mathrm{~g}$ de ácido oléico/100 g).

\section{FIGURA 1 - CONTEÚDO DE ACIDEZ DOS ÓLEOS DE SOJA E DE ARROZ APÓS SUCESSIVAS FRITURAS}

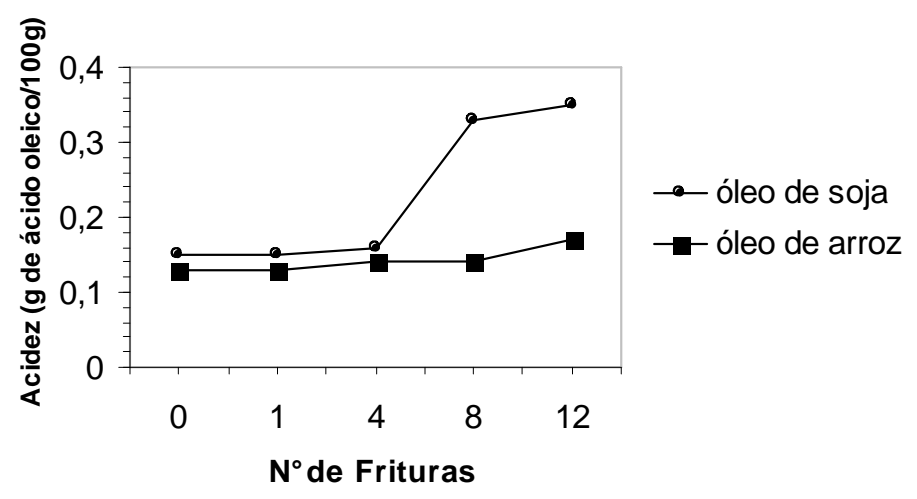

O conteúdo da acidez inicial do óleo de soja $(0,15 \mathrm{~g}$ de ácido oléico/ $100 \mathrm{~g})$ mostrou-se praticamente igual à do óleo de arroz $(0,13 \mathrm{~g}$ de ácido oléico $/ 100 \mathrm{~g}$ ). O teor de acidez do óleo de soja não apresentou diferença significativa até o $4^{\circ}$ período de fritura $(0,16 \mathrm{~g}$ de ácido oléico/ $100 \mathrm{~g}$ ) e o óleo de arroz até o $8^{\circ}$ período $(0,14 \mathrm{~g}$ de ácido oléico/100 g).

No oitavo período de fritura, o valor de acidez do óleo de soja evidenciou acréscimo brusco $(0,33 \mathrm{~g}$ de ácido oléico/100 g), significativamente superior ao valor de acidez do óleo de arroz $(0,14 \mathrm{~g}$ de ácido oléico/ 100 g). O mesmo só ocorreu para o óleo de arroz após o 12 período de fritura $(0,17 \mathrm{~g}$ de ácido oléico/100 $\mathrm{g})$, sendo os valores bem inferiores ao de acidez do óleo de soja (0,35 g de ácido oléico/100 g).

O óleo de arroz utilizado no processo de fritura manteve o conteúdo de ácidos graxos livres bem inferior ao óleo de soja, demonstrando-se mais resistente à hidrólise química nas condições do experimento.

A legislação brasileira vigente (ANVISA, 1999) para os óleos de soja e de arroz refinados tolera no máximo $0,3 \mathrm{~g}$ de ácido oléico/100 $\mathrm{g}$, valor atingido pelo óleo de soja a partir do quarto período de fritura. $\mathrm{O}$ 
conteúdo de acidez do óleo de arroz enquadrou-se nos limites estabelecidos pela legislação até o 12ํㅜ período de fritura.

O monitoramento do conteúdo de peróxidos nos óleos submetidos à fritura estão apresentados na Figura 2.

\section{FIGURA 2 - ÍNDICE DE PERÓXIDO DOS ÓLEOS DE SOJA E DE ARROZ APÓS SUCESSIVAS FRITURAS}

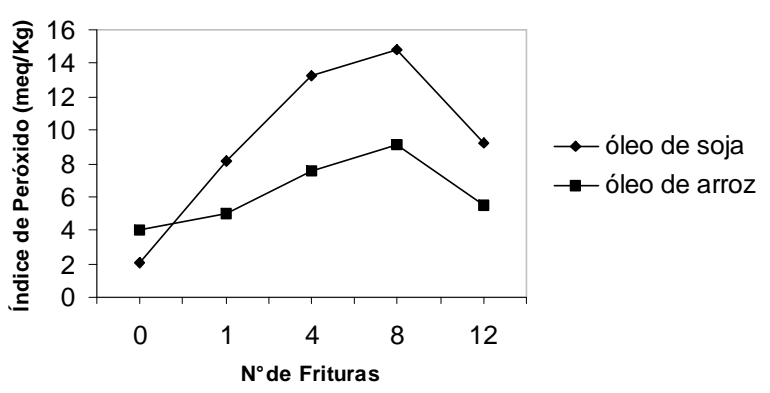

O índice de peróxido está relacionado com a degradação oxidativa dos óleos, caracterizando-se como os produtos iniciais desse tipo de reação. O óleo de arroz apresentou índice de peróxido $(4,03 \mathrm{meq} / \mathrm{Kg})$ inicial significativamente superior ao do óleo de soja $(2,08 \mathrm{meq} / \mathrm{Kg})$. No entanto, o índice de peróxido do óleo de soja mostrou-se significativamente superior ao do óleo de arroz a partir do primeiro período de fritura. A taxa de acréscimo do índice de peróxido no óleo de soja manteve-se bem superior em relação ao do óleo de arroz até o oitavo período de fritura.

O óleo de arroz evidenciou maior estabilidade em relação às reações oxidativas do que o óleo de soja nas condições deste estudo, concordando com a composição em ácidos graxos dos óleos. O óleo de soja apresenta conteúdo inferior em ácidos graxos saturados e superior em ácidos graxos poliinsaturados, os quais são mais susceptíveis aos processos oxidativos (ZAMBIAZI, 1997).

A redução do índice de peróxido no $12^{\circ}$ período de fritura para ambos os óleos demonstra peróxidos formados em temperaturas elevadas. $A$ 
partir de determinado ponto, a taxa de degradação dos peróxidos tornase superior à sua taxa de formação originado inúmeros compostos secundários no meio. A extensão e o tipo de reações definem a perda de qualidade e até o aumento de toxidez desse óleo (CHRISTOPOULOU e PERKINS, 1989; DOBARGANES e PÉREZCAMINO, 1991; BOGNÁR, 1998).

Pela legislação brasileira (ANVISA, 1999), o índice de peróxido não pode ser superior a $10 \mathrm{meq} / \mathrm{Kg}$ para ambos os óleos comerciais. Embora não-específico para meios de fritura, o meio contendo óleo de soja ultrapassou esse valor já no quarto período de fritura. Para o meio contendo óleo de arroz, o índice de peróxido manteve-se em níveis inferiores aos estabelecidos pela legislação em todos os períodos de fritura.

Assim como para o conteúdo de acidez, o óleo de arroz mostrou-se mais resistente aos processos oxidativos que o meio contendo óleo de soja.

\subsection{ANÁLISE SENSORIAL}

Óleos e gorduras, submetidos ao aquecimento contínuo no processo de fritura por imersão, sofrem alterações que a curto prazo modificam sua coloração original. Além disso, originam odores e sabores indesejáveis pela formação de inúmeros compostos voláteis (FRITSCH, 1981; FIRESTONE, STIER e BLUMENTHAL, 1991).

A Tabela 1 apresenta os resultados da avaliação de odor e sabor dos óleos de arroz e soja submetidos ao processo descontínuo de fritura.

\section{TABELA 1 - ANÁLISE SENSORIAL DE COR E SABOR DE ÓLEOS SUBMETIDOS À FRITURA DESCONTÍNUA}

\begin{tabular}{ccccc}
\hline \multirow{2}{*}{$\begin{array}{c}\text { Número } \\
\text { frituras }\end{array}$} & \multicolumn{2}{c}{ Cor } & \multicolumn{2}{c}{ Odor } \\
\cline { 2 - 5 } & Óleo de soja & Óleo de arroz & Óleo de soja & Óleo de arroz \\
\hline 1 & $0,9 \mathrm{a}$ & $0,6 \mathrm{a}$ & $1,2 \mathrm{a}$ & $1,7 \mathrm{a}$ \\
4 & $4,9 \mathrm{~b}$ & $2,3 \mathrm{~b}$ & $4,5 \mathrm{~b}$ & $2,3 \mathrm{a}$ \\
8 & $6,2 \mathrm{c}$ & $3,1 \mathrm{bc}$ & $7,3 \mathrm{c}$ & $4,9 \mathrm{~b}$ \\
12 & $8,3 \mathrm{~d}$ & $3,7 \mathrm{c}$ & $8,7 \mathrm{~d}$ & $6,6 \mathrm{c}$ \\
\hline
\end{tabular}

Letras iguais na mesma coluna não representam diferenças significativas pelo teste de Tukey ao nível de $5 \%$ de probabilidade. 
Aumento na coloração do óleo de soja foi detectado a partir do quarto período de fritura, que se intensificou progressivamente até $012^{\circ}$ período. A equipe de julgadores observou para o óleo de arroz apenas pequenas alterações na cor em relação ao óleo original, mesmo após o $12^{\circ}$ período de estocagem.

A cor mais intensa adquirida pelo óleo de soja coincidiu com os índices de peróxido e de acidez mais elevados do meio. No entanto, outros fatores podem contribuir para a alteração da coloração. $A$ isomerização das duplas ligações induz a migração e formação de duplas conjugadas, as quais absorvem maiores quantidades de luz e intensificam as cores laranja e marrom no óleo (LIMA e GONÇALVES, 1994). Além disso, pode ocorrer a absorção ou passagem dos pigmentos escuros dos alimentos para o óleo e também o escurecimento do alimento pelas reações de Maillard, influindo na perda de qualidade do óleo (CELLA, REGITANO-D'ARCE e SPOTO, 2002).

O odor do óleo de soja apresentou pronunciada diferença em relação ao original a partir da quarta fritura e o óleo de arroz a partir da oitava fritura. O odor percebido pela equipe de julgadores foi mais pronunciado para o óleo de soja em todos os períodos de fritura, o qual se tornou mais intenso no decorrer do processo. Essa mudança de odor pode ocorrer pela formação de compostos secundários, resultantes, principalmente, do processo oxidativo (MARQUEZ-RUIZ, PÉREZCAMINO e DOBARGANES, 1990). A intensidade do odor percebido pelos julgadores, também coincidiu com os dados do índice de peróxido (superior nas amostras de óleo de soja).

A Tabela 2 apresenta os resultados da análise sensorial realizada com as batatas fritas nos óleos de soja e arroz.

\section{TABELA 2 - ANÁLISE SENSORIAL DA BATATA FRITA NOS ÓLEOS DE SOJA E ARROZ EM DIFERENTES PERÍODOS DE FRITURA DESCONTÍNUA}

\begin{tabular}{lllllll}
\hline \multirow{2}{*}{$\begin{array}{l}\text { Número } \\
\text { frituras }\end{array}$} & \multicolumn{2}{c}{ Cor } & \multicolumn{2}{c}{ Odor } & \multicolumn{2}{c}{ Sabor } \\
\cline { 2 - 6 } & Óleo soja & Óleo arroz & Óleo soja & Óleo arroz & Óleo soja & Óleo arroz \\
\hline 1 & $4,2 \mathrm{a}$ & $4,6 \mathrm{a}$ & $3,5 \mathrm{a}$ & $4,4 \mathrm{a}$ & $2,3 \mathrm{a}$ & $3,1 \mathrm{a}$ \\
4 & $4,5 \mathrm{a}$ & $4,4 \mathrm{a}$ & $3,9 \mathrm{a}$ & $4,3 \mathrm{a}$ & $2,5 \mathrm{a}$ & $2,7 \mathrm{a}$ \\
8 & $5,7 \mathrm{~b}$ & $4,7 \mathrm{a}$ & $6,1 \mathrm{~b}$ & $4,6 \mathrm{a}$ & $6,6 \mathrm{~b}$ & $4,7 \mathrm{~b}$ \\
12 & $7,5 \mathrm{c}$ & $6,1 \mathrm{~b}$ & $7,4 \mathrm{c}$ & $5,4 \mathrm{~b}$ & $6,9 \mathrm{~b}$ & $4,9 \mathrm{~b}$ \\
\hline
\end{tabular}


A coloração da batata frita se alterou durante o processo de fritura, ficando mais intensa (escura) no óleo de soja utilizado pela oitava vez e no óleo de arroz utilizado pela décima segunda vez. Tais alterações não foram tão pronunciadas quanto as ocorridas na cor dos óleos de fritura, principalmente do óleo de soja.

A cor da batata normalmente se intensifica (cor dourada escura) durante o processo de fritura devido seu alto teor de amido, o que desencadeia a reação de Maillard com a formação de pigmentos que escurecem 0 alimento (STEVENSON, VAISEY-GENSER e ESKIN, 1984; O'DONNELL, 1995). A intensificação da cor das batatas fritas em meios utilizados para frituras anteriores, também ocorre pela incorporação da cor do próprio óleo (meio de fritura) que se torna mais escuro após vários períodos de fritura.

Verificou-se praticamente a mesma intensidade quanto ao odor das batatas fritas em óleos de soja e de arroz até quatro períodos de uso. A partir da 8ª reutilização, o odor das batatas fritas em óleo de soja apresentou intensidade significativamente superior. As batatas fritas em óleo de arroz evidenciaram acréscimo significativo na percepção do odor apenas no $12^{\circ}$ período de fritura e mesmo assim, o odor das batatas fritas assemelhou-se ao verificado no $8^{\circ}$ período de uso do óleo de soja.

O sabor da batata frita praticamente não se alterou, em ambos os óleos, até quatro períodos de fritura. Observou-se, então, aumento gradual de sabor indesejável, caracterizado como amargo à queimado para as batatas fritas em óleo de soja. O sabor das batatas fritas em óleo de arroz também sofreu negativa influência a partir da $8^{\underline{a}}$ reutilização, no entanto, as amostras foram caracterizadas apenas como oleosas.

\section{CONCLUSÃO}

Tanto a acidez quanto a formação de peróxidos ocorrem rapidamente no processo de fritura, sendo originados em maior quantidade no óleo de soja que no óleo de arroz.

Sensorialmente, o óleo de soja apresentou alterações significativas 
na cor e no odor a partir do quarto período de fritura e o óleo de arroz a partir do oitavo período.

A batata frita em óleo de soja apresentou alterações sensoriais na cor, odor e sabor a partir do oitavo período de fritura. Na batata frita em óleo de arroz as alterações de cor e odor ocorreram a partir do $12^{\circ}$ período e de sabor a partir do oitavo período.

O óleo de arroz evidenciou maior estabilidade que o óleo de soja para frituras descontínuas sucessivas de batatas em forma de tiras, podendo ser utilizado em maior número de frituras.

\begin{abstract}
STUDY OF SOYBEAN AND OF RICE BRAN OIL BEHAVIOUR REUSED IN POTATO DESCONTINUOS FRYING PROCESS

This study had as objective evaluate quality parameters of rice bran and soybean oils after successive fries. Twelve lots of $200 \mathrm{~g}$ of potato cut type toothpick were taken to the frying into two different oil types, rice bran and soybean. The applied analytical methods for evaluation of the alteration in the oils included free fatty acid and peroxide index determinations, before and after the frying process. After predeterminated frying periods, the sensory evaluation of the oil samples were performed for color and odor attributes, and sensory evaluation of the fried potatoes for color, odor and flavor attributes. The rice bran oil presented higher stability, and it affected less the potato characteristics during the successive frying processes. The soybean oil presented significant color and odor sensory alterations, starting from the fourth frying period, and the rice bran oil starting from the eighth period. The potatoes presented sensory alterations of color, odor and flavor, in soybean oils used by the eighth frying period, while they just presented alterations in rice bran oils used above the twelfth time.
\end{abstract}

KEY-WORDS: VEGETABLE OILS - DEGRADATION; VEGETABLE OILS STABILITY; SENSORY ANALYSIS.

\title{
REFERÊNCIAS
}

1 ABNT. Associação Brasileira de Normas Técnicas. NBR 14141: escalas utilizadas em análise sensorial de alimentos e bebidas. Rio de Janeiro, 1998.

2 ANS, V. G.; MATTOS, E. S.; JORGE, N. Avaliação da qualidade dos óleos de fritura usados em restaurantes, lanchonetes e similares. 
Ciência e Tecnologia de Alimentos, Campinas, v.19, n.3, p.413419, 1999.

3 ANVISA. Agência Nacional de Vigilância Sanitária. Resolução RDC no 482, de 23 de setembro de 1999. Regulamento Técnico para Fixação de Identidade e Qualidade de Óleos e Gorduras Vegetais. Disponível em: < http://e-legis.bvs.br/leisref/public >. Acesso em: 20 abr. 2005.

4 AOCS. American Oil Chemists' Society. Official and tentative methods of the American Oils Chemists' Society, Champaign, IL., 1992.

5 ARAUJO, J.M.A. Química de alimentos: teoria e prática. 2. ed. Viçosa: Universidade Federal de Viçosa, 1999. 416 p.

6 BOGNÁR, A. Estudo comparativo de la influencia de la fritura y otras técnicas de cocinado em el valor nutritivo. Instituto de la Grasa (CSIC), Sevilla, v.49, n.3-4, p.250-260, 1998.

7 CELLA, R. C. F.; REGITANO-D'ARCE, M.A.B.; SPOTO, M.H. Comportamento do óleo de soja refinado utilizado em fritura por imersão com alimentos de origem vegetal. Ciência e Tecnologia de Alimentos, v. 22, n. 2, p.56-58, maio/ago., 2002.

8 CHRISTOPOULOU, C. N.; PERKINS, E. G. Isolation and characterization of dimers formed in used soybean oil. Journal American Oil Chemists' Society, v. 66, n. 9, p. 1360-1370, 1989.

9 COSTANETO, P.R. da; FREITAS, R.J.S. de; WASZCZYNSKYJ, N. Avaliação sensorial de pastéis fritos em óleo de soja com diferentes tempos de aquecimento. Boletim do CEPPA, Curitiba, v. 13, n. 2, p.91-98, jul./dez. 1995.

10 DOBARGANES, M. C.; PÉREZ-CAMINO, M. C. Frying process: selection of fats and quality control. In: INTERNATIONAL MEETING ON FATS \& OILS TECHNOLOGY SYMPOSIUM AND EXHIBITION, 1991, Campinas. Anais... Campinas: SBOG, 1991, p. 58-66.

11 FIRESTONE, D.; STIER, R. F.; BLUMENTHAL, M. M. Regulation of frying fats and oils. Food Technology, v. 45, n. 2, p. 90-94, 1991.

12 FRITSCH, C.W. Measurements of frying fat deterioration: a brief 
review. Journal of the American Oil Chemists' Society, v. 5, n. 3, p. $272-274,1981$.

LIMA, J.R.; GONÇALVES, L.A.G. Avaliação da qualidade de óleo de soja utilizado para fritura. Campinas, 1994.60 p. Dissertação (Mestrado), Faculdade de Engenharia de Alimentos, Universidade Estadual de Campinas.

LOLOS, M.; OREOPOULOU, V.; TZIA, C. Oxidative stability of potato chips: effect of frying oil type, temperature and antioxidants. Journal of Science Food and Agriculture, v 24, p. $1524-1528$, 1999.

MÁRQUEZ-RUIZ, G.; PÉREZ-CAMINO, M. C.; DOBARGANES, M. C. Evaluación nutricional de grasas termoxidadas y de fritura. Aceites y Grasas, v. 41, p. 432-439, 1990.

MASSON, L.; et al. Comportamiento de aceites poliinsaturados en preparación de batatas fritas para consumo inmediato: formación de nuevos compuestos y comparación de métodos analíticos. Grasas y aceites, Sevilla, España, v.48, n.5, p.273281, 1997.

MORETTO, E.; FETT, R. Tecnologia de óleos e gorduras na indústria de alimentos. São Paulo: Livraria Varela, 1998. 150 p.

O'DONNELL, C.D. Fats and oils: forces in fried food quality. Prepared Foods, v.1, p. 77-78, 1995.

PINTO, E.P.; BORGES, C.D.; TEIXEIRA, A.M.; ZAMBIAZI, R.Z. Características de batata frita em óleos com diferentes graus de insaturação. Boletim do CEPPA, Curitiba, v.21, n.2, p.293-302, 2003.

ROJO, J. A.; PERKINS, E. G. Cyclic fatty acid monomer formation in frying fats. I. Determination and structural study. Journal of the American Oil Chemists' Society, v. 64, n. 3, p. 414-421, 1987.

STEVENSON, S. G.; VAISEY-GENSER, M.; ESKIN, N. A. M. Quality control in the use of deep frying oils. Journal of the American Oil Chemists' Society, v. 61, n. 6, p. 1102-1108, 1984.

ZAMBIAZI, R.Z. Oxidation reactions of vegetable oils and fats. Revista da Sociedade Brasileira de Ciência e Tecnologia de 
Alimentos, Campinas, v.33, n.1, p.1-7, 1999.

23 ZAMBIAZI, R. Tecnologia de óleos e gorduras. Pelotas: UFPel, 2005. $123 \mathrm{p}$.

24 ZAMBIAZI, R.Z; ZAMBIAZI, M.W. Vegetable oil oxidation: effect of endogenous components. Revista da Sociedade Brasileira de Ciência e Tecnologia de Alimentos, Campinas, v.34, n.1, p.22$32,2000$.

25 ZAMBIAZI, R.Z. The role of endogenous lipid components on vegetable oil stability. Winnipeg, 1997. 304 p. Tese (Doutorado), University of Manitoba, Canada. 